\title{
Antimicrobial potential of various substituted azetidine derivatives
}

\begin{abstract}
Azetidine derivatives are reported to show a variety of antimicrobial, antitubercular, anticonvulsant, anti-inflammatory and cardiovascular activities. This review is focused on antimicrobial activities of azetidine derivatives. The use of antimicrobial agents is limited due to rapidly developing drug resistance and side effects. Therefore, the development of new antimicrobial drugs is an essential aim. Much of research efforts are directed towards the design of new effective antimicribials.
\end{abstract}

Keywords: azetidinone, antimicrobial, antitubercular, antioxidant, anti-inflammatory
Volume 2 Issue 2 - 2018

\author{
Mohammad Asif \\ Department of Pharmacy, Institute of Management and \\ Technology, India \\ Correspondence: Mohammad Asif, Department of Pharmacy, \\ GRD(PG) Institute of Management and Technology, Dehradun, \\ 248009, Uttarakhand, India, Tel +91989708 8910, \\ Email aasif32।@gmail.com
}

Received: March 01, 2017 | Published: March 07, 2018

\section{Introduction}

Many serious and life threatening diseases such as tuberculosis are caused by bacteria or fungi infections. Organ transplantation or surgery caused microbial infections are common problem. ${ }^{1,2}$ Natural, synthetic and semi synthetic antimicrobial drugs have been used against the life threatening infectious diseases. ${ }^{3}$ Deaths from bacterial and fungal infection have dropped currently, but still those are the major cause of death in the world. ${ }^{4}$ Over the few past decades the bacterial resistance to antibiotics, anti-fungal and anti-TB drugs has become one of the most challenging problems in the infections treatments. TB is a chronic grannulomatous disease $\mathrm{e}^{5}$ and world's oldest known infectious disease that causes about three million deaths each year. The causative organism of disease is Mycobacterium tuberculosis (Mtb). ${ }^{6}$ In the last decade, researchers made a continuous effort to fight these diseases and several new chemotherapeutic agents have been successfully introduced. Several azetidine containing drugs exhibited promising results. ${ }^{1,2}$ The urgency to develop new and effective drugs is due to the resistance development by strains against the current medications and growing problem of co-infection in immune-compromised patients. ${ }^{7,8}$ Therefore, more research affects that to develop new and better drugs against infections. ${ }^{9}$ The 2-Azetidinones are frequently encountered heterocycles in compounds of biological interest. They have been shown to possess a broad spectrum of biological activity. ${ }^{10}$ 2-Azetidinone skeleton is well established as the pharmacophore of $\beta$-lactam antibiotics, the most widely employed class of antibiotics. ${ }^{11}$ The structural diversity of biologically active $\beta$-lactam antibiotics led to the development of methods for the construction of appropriately substituted azetidine with control of functional group and stereochemistry. The penicillin and cephalosporin antibiotics possess cis- $\beta$-lactam units, whereas the thienamycins and trinems have trans$\beta$-lactam moieties. The synthesis of $\beta$-lactam became a desirable goal based on the discovery of penicillin and cephalosporin. Although most penicillin and cephalosporin related compounds are obtained by biosynthesis, chemical modification of intermediates for bioassay of the antibacterial activity of the resulting compounds has become of utmost importance because of the growing resistance of bacteria against penicillin-and cephalosporin-like compounds and the need for compounds with more specific antibacterial activity. ${ }^{10,11}$
Azetidine derivatives are reported to show a variety of antimicrobial, antitubercular, anticonvulsant, anti-inflammatory, antimalarial, anticancer, antiviral, antioxidant and cardiovascular activities. ${ }^{12-24}$ These studies showed that even a minor change in the substitution pattern has a major effect on the activities of azetidine derivatives. The azetidinone derivatives have also been recognized as tumor necrosis factor-alpha (TNF-alpha) converting enzyme (TACE) inhibitors and agents with new biological activities, such as anticancer, anticoccidial, cardiovascular, antiviral, mutagenic, anticonvulsant and anti-inflammatory. ${ }^{25-32}$ Some 2-oxo-azetidine derivatives of isoniazid have been tested for anti-bacterial, antifungal and anti-TB activity. The 4-oxo-Azetidines are four membered cyclic amides derived from Schiff bases which contain $\beta$-lactam unit as its essential structural feature of its molecule. ${ }^{33}$ The utility of 4-oxo-azetidines as synthons for various biologically active compounds, as well as their recognition as cholesterol absorption inhibitors and enzyme inhibitors has been studied. ${ }^{34}$

\section{Antimicrobial activities}

Various azetidines 1(a-m) (Figure 1) were tested for their antibacterial, antifungal and antitubercular activity which displayed acceptable results.

The antibacterial, antifungal and antitubercular activities of compounds $1(\mathrm{a}-\mathrm{m})$ have been assayed in vitro against selected Gram positive bacteria, Bacillus subtilis, Staphylococcus aureus and Gram negative bacteria, Escherichia coli, Klebsiella pneumoniae fungi, Aspergillus niger, Aspergillus flavus, Candida albicans Fusarium oxisporium and Mtb H37Rv strain, MIC values of compounds 1(a-m) were determined antibacterial, antifungal activities and antitubercular activity. Streptomycin and Griseofulvin were used as standard for antibacterial and antifungal activity and showed MIC range for all bacterial strain $1.25-6.25 \mu \mathrm{g} / \mathrm{mL}$, for all fungal strain activity was found to be $6.25-12.5 \mu \mathrm{g} / \mathrm{mL}$ and for antitubercular activity, isoniazid and rifampicin taken as standards. Nitro group containing compounds (1h, $1 \mathrm{i}$ and $1 \mathrm{j}$ ) showed higher activity than chloro (1c, $1 \mathrm{~d})$, or bromo group containing compounds (1e, 1f). Chloro and bromo derivatives also have higher activity than other rested compounds. On the basis of SAR, concluded that the activity of compounds depends 
on electron withdrawing nature of the substituted groups. The sequence of the activity is following $\mathrm{NO}_{2}>\mathrm{Cl}>\mathrm{Br}>\mathrm{OH}>\mathrm{OCH}_{3}$ $>\mathrm{CH}_{3}$. The investigation of antimicrobial (antibacterial, antifungal and antitubercular) data revealed that compounds (1c), (1d), (1e), (1f), (1h), (1i) and (1j) displayed high activity in the series, the compounds $(1 \mathrm{~b}),(1 \mathrm{~g})$ and $(1 \mathrm{~m})$ showed moderate activity and the rest of the compounds showed less activity against all the strains compared with standard drugs. Compounds $1(\mathrm{a}-\mathrm{m})$ were screened for their antibacterial, antifungal and anti-TB activity against selected microorganisms. ${ }^{35}$

Compound
4-chlorophenyl

Figure I Various azetidines I (a-m) were tested for their antibacterial, antifungal and antitubercular activity.

A series of azetidinones (2a-m) (Figure 2) have been were tested for their antibacterial and antifungal activities against some selected bacteria and fungi and for their antitubercular activity against Mycobacterium tuberculosis, and their minimum inhibitory concentration (MIC) values were determined. These compounds were also exhibited anti-inflammatory activities. ${ }^{36}$ Compounds $2 \mathrm{a}-\mathrm{m}$ was tested for their antibacterial, antifungal, antitubercular and antiinflammatory activities. ${ }^{36}$

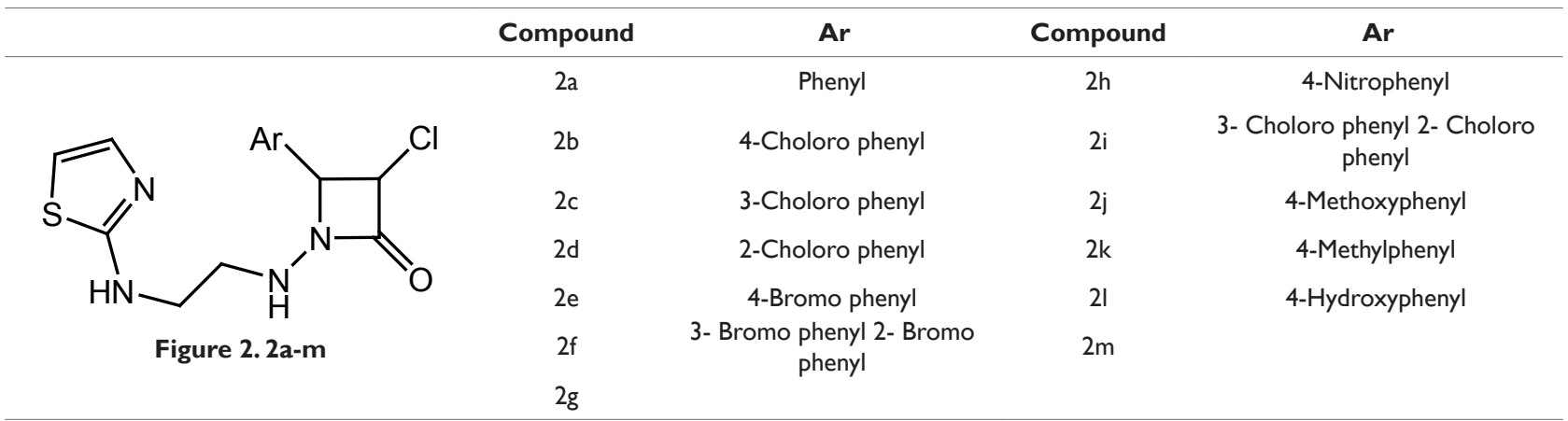

Figure $2 \mathrm{~A}$ series of azetidinones $(2 \mathrm{a}-\mathrm{m})$ have been were tested for their antibacterial and antifungal activities against some selected bacteria and fungi.

The antibacterial, antifungal and antitubercular activities of compounds $2 \mathrm{a}-\mathrm{m}$ were assayed in vitro against selected bacteria: Bacillus subtilis, Escherichia coli, Staphylococcus aureus and Klebsiella pneumoniae, and fungi: Aspergillus niger, A. flavus, Candida albicans and Fusarium oxysporum, and Mtb (H37Rv) strain. The results of the antimicrobial screening data revealed that all the compounds $2 \mathrm{a}-\mathrm{m}$ showed activity against the selected microorganisms. The nitro group-containing compounds $(2 \mathrm{~h}, 2 \mathrm{i}$ and $2 \mathrm{j})$ showed higher activity than the chloro $(2 \mathrm{c}$ and $2 \mathrm{~d})$, or bromo group containing compounds (2e and $2 \mathrm{f}$ ). The chloro and bromo derivatives also had a higher activity than the other rested compounds. It can be concluded that the activity of the compounds depends on electron withdrawing nature of the substituent groups. The sequence of the activity is the following: $\mathrm{NO}_{2}>\mathrm{Cl}>\mathrm{Br}>\mathrm{OH}>>\mathrm{OCH}_{3}>\mathrm{CH}_{3}$. The investigation of antimicrobial (antibacterial, antifungal and anti-TB) data revealed that the compounds $2 \mathrm{c}, 2 \mathrm{~d}, 2 \mathrm{e}, 2 \mathrm{f}, 2 \mathrm{~h}, 2 \mathrm{i}$ and $2 \mathrm{j}$ displayed high activity, the compounds $2 \mathrm{~b}, 2 \mathrm{~g}$ and $2 \mathrm{~m}$ showed moderate activity and the other compounds showed low activity against all the strains compared with the standard drugs. In the anti-inflammatory activity test, compounds $2 \mathrm{c}, 2 \mathrm{~d}, 2 \mathrm{e}, 2 \mathrm{f}, 2 \mathrm{~h}, 2 \mathrm{i}$ and $2 \mathrm{j}$ showed high activity while the other compounds displayed moderate to low activity. ${ }^{36}$

A series of azetidines 3(a-j) (Figure 3) containing compounds 3(aj) were screened for their antibacterial, antifungal and antitubercular activities in vitro against selected bacteria, B. subtilis, E. coli, S. aureus, and fungi A. niger, A. flavus, C. albicans and Mtb H37Rv strain respectively. Streptomycin and griseofulvin used as standard for antibacterial and antifungal activities respectively and isoniazid and rifampicin for anti-TB activity.

The investigation of antimicrobial (antibacterial, antifungal and anti-TB) of the compounds (3c), (3d), (3e), (3f), (3h), (3i) and (3j) displayed high activity in the series, the compounds $(3 \mathrm{~b})$ and $(3 \mathrm{~g})$ showed moderate activity and compound 3 a showed less activity against all the strains compared with standard drugs. ${ }^{37}$

A series of azetidine derivatives (4a-f) (Figure 4) were tested for their anti-bacterial activity against Staphylococcus aureus and Echerichia coli, Antifungal activity against $\mathrm{C}$ Albicans and antitubercular activity against $M$. tuberculosis and exhibited significant activity against bacterial, fungal and mycobacterium strains.

Antimicrobial screening data of compounds showed good to moderate activity, against bacterial, fungal and M. tuberculosis strain, as compared to reference drug. Compound $4 \mathrm{a}$ showed moderate activity against all strains. Compound $4 \mathrm{~b}$ showed good activity against E Coli while showed moderate activity against $S$. aureus, C. Albicans and M. tuberculosis. Compound $4 \mathrm{c}$ and $4 \mathrm{f}$ showed good activity against all strains. Compound $4 \mathrm{~d}$ and $4 \mathrm{e}$ were showed excellent 
antibacterial, antifungal and anti-TB activity against tested strains. The antimicrobial activity is due the presence of $\beta$-Lactam ring and increased by the addition phenyl moiety/heterocyclic compounds at 4 position of $\beta$-Lactam ring. Amongst these $4 \mathrm{e}$ showed the highest activity against $\mathrm{M}$. tuberculosis as compare to other compounds, is due to the presence the indole moiety at the 4 position of azetidine ring. ${ }^{38}$

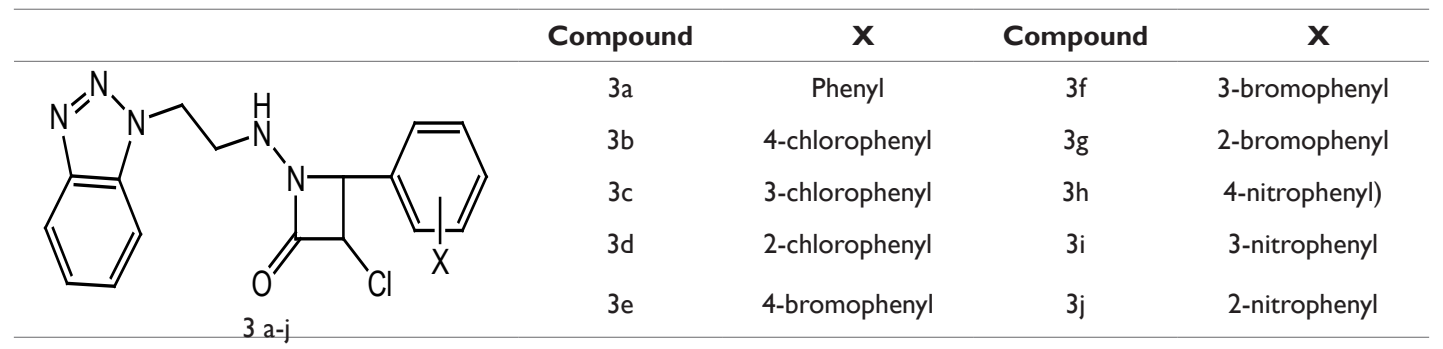

Figure $3 \mathrm{~A}$ series of azetidines $3(\mathrm{a}-\mathrm{j})$ containing compounds $3(\mathrm{a}-\mathrm{j})$ were screened for their antibacterial, antifungal and antitubercular activities.

Compound

Figure 4 A series of azetidine derivatives (4a-f) were tested for their anti-bacterial activity against Staphylococcus aureus and Echerichia coli, Antifungal activity.

\section{Antioxidant activity}

The 4-oxo-azetidines were also tested for their antioxidant activity. The activity of all compounds was identified by using nitric oxide and superoxide radical scavenging methods against alkaline dimethyl sulfoxide (DMSO). The derivatives $(4 \mathrm{a}, 4 \mathrm{c})$ with the chlorine substituent either at ortho or para on phenyl ring exhibited maximum activity in both methods. The least activity is shown by the compound (4g) having ortho nitro group on the benzene ring (Figure 5).

All the 4-oxo-azetidine derivatives (4a-4g) (Figure 5) were tested for their in vitro free radical scavenging Nitric oxide (NO) and scavenging of superoxide radical with the alkaline DMSO method. The nitric oxide assay is widely used to evaluate the free radical scavenging effectiveness of various antioxidant substances. The scavenging ability of the synthesized compounds was compared with ascorbic acid as a standard. Compounds $4 \mathrm{c}$ and $4 \mathrm{e}$ produced better scavenging ability. Compounds $4 \mathrm{a}, 4 \mathrm{~b}, 4 \mathrm{~d}$ and $4 \mathrm{e}$ showed moderate radical scavenging activity and $4 \mathrm{~g}$ compound showed least activity when compared to the standard. Even though superoxide radical is a weak oxidant, it gives rise to the generation of powerful and dangerous hydroxyl radical along with single oxygen, both of which lead to oxidative stress. The compound $4 \mathrm{c}$ showed better scavenging activity whereas $4 \mathrm{a}, 4 \mathrm{~b}$ and $4 \mathrm{f}$ exhibited moderate activity. Least activity is identified for the compounds $4 \mathrm{~d}, 4 \mathrm{e}$ and $4 \mathrm{~g}$. 4-oxoazetidines exhibited significant to moderate activity when compared with standard ascorbic acid. Strong antioxidant activity was observed for $4 \mathrm{c}$ in both methods. ${ }^{39}$

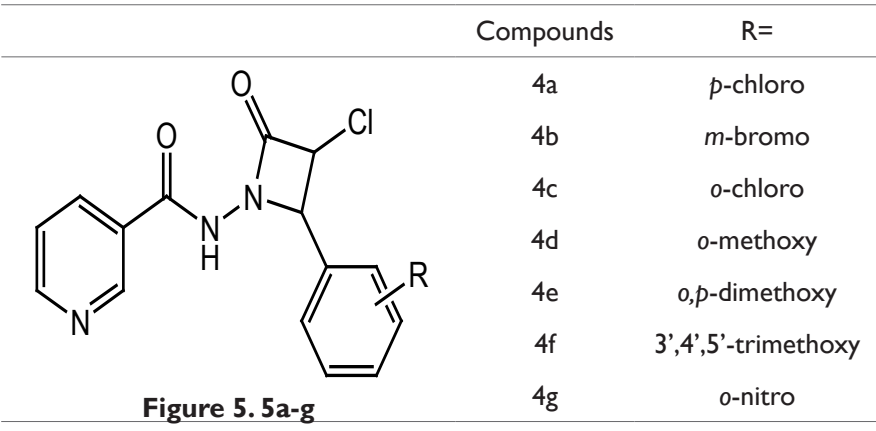

Figure 5 4-oxo-azetidines were also tested for their antioxidant activity.

\section{Conclusion}

The antimicrobial and antitubercular activity of the synthesized compounds bearing an azetidinone moiety revealed that all the tested compounds showed antibacterial, antifungal and antitubercular activities against the selected microbial strains. Some of the compounds displayed promising activities and are of interest for further transformations towards more potent derivatives. These compounds posses good anti-bacterial, antifungal and anti-TB activities. Furthermore, the development of new azetidine derivatives which are highly desirable. 


\section{Acknowledgements}

Author contributed toward data analysis, drafting and revising the paper and agree to be accountable for all aspects of the work.

\section{Conflict of interest}

There is no conflict of interest.

\section{References}

1. Fiddler DF. Legal issues associated with antimicrobial drug resistance. Emerge Infect Dis. 1998;4(2):169-177.

2. Patel M, Parmar V, Shah D. QSAR Analysis of Anti T. B. Drug Isoniazide Based Azetidino-2-one Derivatives as Antimicrobial Agents. Res $J$ Computer and IT Sci. 2013;1(4):1-4.

3. Babu Narendra SN, Rangappa KS. Design, Synthesis, antibacterial and antitubercular activity of cationic antimicriobial peptides, ovine bactenecin5. Ind J Chem. 2008;47B:297-304.

4. Gilani SJ, Khan SA, Alam O, et al. Synthesis and in vitro antimicrobial evalution of condensed heterocycle 6-substituted 1,2,4-triazolo [3,4 b]-1,3,4-thiadiazole and 1,3,4-oxadiazole derivatives of isoniazid. Acta Pol Pharm. 2011;68(2):205-211.

5. Tripathi KD. Essentials of Medical Pharmacology. $5^{\text {th }}$ ed. New Delhi: Japees Brothers Medical Publishers Pvt Ltd; 2003. 689 p.

6. William DA, Lemke TL. Foye's Principals of Medicinal Chemistry. $5^{\text {th }}$ ed. New York: Lippincott Wiliams and Wilkins; 2002:905-1128.

7. Husain A. Amide derivatives of sulphonamides and Isoniazid: synthesis and biological evalution. Acta Pol Pharm. 2009;66(6):513-521.

8. Yar MS, Siddiqui AA, Ali MA. Synthesis and anti tuberculostatic activity of novel 1,3,4-oxadiazole derivatives. J Chinese Chem Soc. 2007;54(1):5-8.

9. Pattan SR, Reddy VVK, Manvi FV, et al. Synthesis of N-3-(4-(4 chlorophenyl thiazole-2-yl)-(2-(amino) methyl)-quinoline-4(3H)one and their derivatives for antitubercular activity. Ind $J$ Chem. 2006;45B:1778-1781.

10. WHO Report. Global Tuberculosis Control; Surveillance, Planning, Financing; World Health Organization: Geneva, Switzerland, 2005.

11. Trivedi, AR, Siddiqui AB, Shah VH. Design, synthesis, characterization and antitubercular activity of some 2-heterocycle-substituted phenothiazines. Arkivoc. 2008;2:210-217.

12. Srivastava SK, Dua R, Srivastava SD. Synthesis and antimicrobial activity of [N1-(N-substitutedarylidene-hydrazino)-acetyl]-2methyl-imidazoles and [N1-(4-substituted aryl-3-chloro-2-oxo-1azetidinyl-amino)-acetyl]-2-methyl-imidazoles. Proc Nat Acad Sci India, Sec A: Phys Sci. 2010;80:117-121.

13. Trivedi PB, Undavia NK, Dave AM, et al. Synthesis and antimicrobial activity of 4-oxothiazolidines, 4-oxoazetidines, malonanilic acid hydrazines and pyrazoline derivatives of phenothiazine. Indian J Chem. 1993;32B(7):760-765.

14. Panwar H, Verma RS, Srivastava VK, et al. Synthesis of some substituted Azetidinonyl and thiazolidinonyl-1,3,4-thiadiazino[6,5-b]indoles as prospective antimicrobial agents. Indian J Chem. 2006;45B:2099-2104.

15. Patel RB, Desai PS, Desai KR, et al. Synthesis of pyrimidine based thiazolidinones and azetidinones: antimicrobial and antitubercular agents. Indian J Chem. 2006;45B:773-778.

16. Siddiqui N, Rana A, Khan SA, et al. Anticonvulsant and Toxicity Evaluation of Newly Synthesized 1-2-(3,4-disubstitutedphenyl)-3chloro-4-oxoazetidin-1-yl-3-(6-substituted-1,3-benzothiazol-2-yl) ureas. Acta Chim Slov. 2009;56:462-469.

17. Srivastava SK, Srivastava SL, Srivastava SD. Synthesis of new 2-chloro phenothiadiazol-2-oxoazetidines-antimicrobial and anti-inflammatory agents. Indian J Chem. 2000;39B:464-467.

18. Kumar A, Gurtu S, Agarwal JC, et al. Synthesis and cardiovascular activity of substituted 4-azetidinones. $J$ Indian Chem Soc. 1983;60(6):608-610.

19. Sutariya B, Raziya SK, Mohan S, et al. Synthesis and antimicrobial activity of some new 2-substituted aminothiazole. Indian $J$ Chem. 2007;46B(5):884-887.

20. Mistry K, Desai KR. Synthesis of pyrazole imines and azetidinones compounds using conventional and microwave technique and studies of their antibacterial activity. Indian J Chem. 2005;44B:1452-1455.

21. Nivsarkar M, Thavaselvam D, Prasanna S, et al. Design, synthesis and biological evaluation of novel bicyclic $\beta$-lactams as potential antimalarials. Bioorg Med Chem Lett. 2005;15(5):1371-1373.

22. Banik BK, Banik I, Becker FF. Synthesis of anticancer $\beta$-lactams mechanism of action. Bioorg Med Chem. 2004;12(10):2523-2528.

23. Zoidis G, Fytas C, Papanastasiou I, et al. Heterocyclic rimantadine analogues with antiviral activity. Bioorg Med Chem. 2006;14(10):33413348 .

24. Dubey A, Srivastava SK, Srivastava SD. Conventional and microwave assisted synthesis of 2-oxo-4-substituted aryl-azetidine derivatives of benzotriazole: A new class of biological compounds. Bioorg Med Chem Lett. 2011;21(1):569-573.

25. Melloni P, Dleea Torre A, Meroni M, et al. Azetidine derivatives of tricyclic antidepressant agents. J Med Chem. 1979;22(2):83-191.

26. Sharma MC, Kohli DV, Sahu NK, et al. 2D-QSAR studies of some 1,3,4-thidiazole-2yl azetidine 2-one as antimicrobial activity. Digest $J$ Nanomat \& Biostruc. 2009;4(2):339-347.

27. Bonde CG, Peepliwal A, Gaikwad NJ. Synthesis and antimycobacteria activity of azetidine-, quinazoline-, and triazolothiadiazole-containing pyrazines. Arch Pharm (Weinheim). 2010;343(4):228-236.

28. Venkateswararao A, Kirubha TSV, Senthamarai R, et al. Synthesis and determination of biological activities of new series of azetidinones. Der Pharm Chemica. 2011;3(1):439-445.

29. AoyamaY,Uenaka M, Kii M, et al. Design, synthesis and pharmacological evaluation of 3-benzylazetidine-2-onebased humanchymase inhibitors. Bioorg \& Med Chem. 2001;9(11):3065-3075.

30. Manahan-Vaughan D, Reiser M, Pin JP, et al. Physiological and pharmacological profile oftransazetidine-2, 4-dicarboxylic acid: Metabotropic glutamate receptor agonism and effects on long-term potentiation. Neuroscience. 1996;72(4):999-1008.

31. Tsai FH, Overberger CG, Zand R. Synthesis and conformation of poly(L-azetidine-2-carboxylic acid- L -proline) and poly([L-proline] 3-L-azetidine-2-carboxylic acid). J Polymer Sci Part A: Polymer Chem. 1992;30(4):551-559.

32. Narute AS, Khedekar PB, Bhusari KP. QSAR studies on 4 thiazolidinones and 2-azetidinones bearing benzothiophene nucleus as potential antitubercular agents. Ind J Chem. 2008;47B(4):586-591.

33. Fareed G, Afza N. Reported antioxidant activity and structure activity relationship of some new Schiff bases derived from 2-amino benzo phenone. Med Chem \& Drug Discov. 2013;4(1):27-34.

34. Gustavo P Romanelli, Autino JC. Recent applications of hetero polyacids and related compounds in heterocyclic synthesis. Mini-Rev Org Chem. 2009;6(4):359-366. 
35. Sharma R, Samadhiya P, Srivastava SD, et al. Synthesis and biological activity of 2-oxo-azetidine derivatives of phenothiazine. Org Commun. 2011;4(2): 42-51.

36. Samadhiya P, Sharma R, Srivastava SK, et al. Synthesis of 2 oxoazetidine derivatives of 2-aminothiazole and their biological activity. J Serb Chem Soc. 2012;77(5):599-605.

37. Sharma R, Samadhiya P, Srivastava SD, et al. Synthesis and Biological Significance of Some 2-Azetidinone Derivatives. J Sci, Islamic Rep Iran. 2012;23(2):139-146.
38. Patel R, Bhandari A. Synthesis and Antimicrobial Screening of Some Azetidine Derivatives. Am J Adv Drug Delivery. 2014;2(1):104-109.

39. Madhavi N, Rani BL. Antioxidant activity of novel 4-oxo-azetidine derivatives synthesized from schiff bases. Int J Res Dev Pharm L Sci. 2014;3(2):905-908. 